\title{
O Ensino da Anamnese Assistido por Tecnologias Digitais durante a Pandemia da Covid-19 no Brasil
}

\author{
Digital Technology-Assisted Teaching of Anamnesis during the Covid-19 Pandemic in Brazil
}

Amanda Júlia de Arruda Magalhães' (D), Matheus Henrique Almeida Rocha' ${ }^{\mathbb{D}}$, Samilla Cristinny Santos' (D), Cecília Borges Dantas' $\mathbb{E}^{\mathbb{D}}$, Glauber José de Melo Cavalcanti Manso' $\mathbb{D}$, Maria Dirlene Alves Ferreira' (iD

\begin{abstract}
RESUMO
Introdução: Em dezembro de 2019, na China, surgiu o primeiro caso de infecção da Sars-CoV-2, causadora da Covid-19. Em março de 2020, após se alastrar pelos continentes, a Organização Mundial da Saúde conferiu característica de pandemia. Para tentar conter o avanço, foi criada a política de distanciamento social, responsável pela interrupção de inúmeras atividades, incluindo aulas presenciais. Assim, ampliou-se a busca por meios de ensino remoto, a fim de amenizar os prejuízos causados na educação. Nesse ínterim, a Universidade Federal de Alagoas propôs realizar a monitoria on-line como forma de promover interação entre estudantes e docentes na pandemia.
\end{abstract}

Relato de Experiência: A construção do curso ocorreu de forma remota por meio de plataformas digitais, como Google Meets® e portal do serviço de conferência web da Rede Nacional de Ensino e Pesquisa (RNP). Foram 54 inscrições de alunos de Medicina, e 38 (70,3\%) cumpriram os requisitos para certificação e finalizaram. Produziram-se 22 podcasts, hospedados nas plataformas Anchor e Spotify®, além de seis formulários do Google ${ }^{\circledR}$ com questões acerca dos conteúdos dos podcasts. Utilizaram-se as plataformas Kahoot ${ }^{\circledR}$, um jogo com questões para aumentar a interação e o Padlet ${ }^{\circledR}$, um “mural virtual” no qual eram postados conteúdos do curso.

Discussão: A implantação das novas Diretrizes Curriculares Nacionais dos Cursos de Graduação Medicina (DCN) instigou nos estudantes autonomia no aprendizado, conferindo espaço para a inserção de tecnologias na educação. Apesar da insuficiência para sanar os prejuízos causados na educação pela pandemia, essas tecnologias conferem aos professores, aos alunos e às instituições de ensino a capacidade de adequação aos meios disponíveis para minimizar prejuízos.

Conclusão: A monitoria on-line permitiu que, mesmo um assunto predominantemente prático como a anamnese, fosse discutido e praticado graças ao suporte tecnológico. Percebe-se, portanto, efetividade na utilização de tecnologias no processo de ensino-aprendizagem quando se utilizam plataformas interativas.

Palavras-chave: Educação a Distância; Anamnese; Educação Médica; Isolamento Social.

\begin{abstract}
Introduction: The first case of SARS-COV-2 virus infection, which caused COVID-19, occurred in China in December 2019. By March 2020, having spread across continents, the disease was officially declared as a pandemic by the World Health Organization. In an attempt to contain the advance of infection, a policy of social distancing was introduced, which implied in the interruption of numerous activities, including face-to-face classes. Hence the demand for means of distance learning expanded in order to mitigate the harm caused in education. In the meantime, the Federal University of Alagoas proposed to carry out online monitoring as a way to promote student-teacher interaction during the pandemic.
\end{abstract}

Experience Report: The course was constructed remotely on digital platforms, such as Google Meets ${ }^{\circledR}$ and National Teaching and Research Network (RNP) online video conference portal. Fifty-four medical students enrolled, of whom 38 (70.3\%) met the certification requirements for certification and completed the course. Twenty-two podcasts were produced, hosted on the Anchor ${ }^{\circledR}$ and Spotify ${ }^{\circledR}$ platforms, in addition to six Google ${ }^{\circledR}$ forms with questions about the contents of the podcasts. Other resources used included Kahoot ${ }^{\circledR}$ platforms, a quiz to increase interaction, and Padlet ${ }^{\circledR}$, a "virtual wall" for posting course content.

Discussion: The implementation of the new National Curricular Guidelines for Undergraduate Medicine Courses (DCN) triggered greater student autonomy in learning, opening the way for the use of technologies in education. Although insufficient to remedy the damage caused in education by the pandemic, these technologies offer teachers, students and educational institutions the ability to adapt to available methods and minimize the harm.

Conclusion: Online monitoring represents technological support that has allowed for even a predominantly practical subject, such as anamnesis, to be discussed and practiced. There is, therefore, demonstrable effectiveness in the use of technologies applied to the teaching-learning process, when using interactive platforms.

Keywords: Distance Learning; Medical History-Taking; Medical Education; Social Distancing.

'Universidade Federal de Alagoas, Arapiraca, Alagoas, Brasil.

Correspondência:

Glauber José de Melo Cavalcanti Manso.

Avenida Doutor Helder Ferreira, 1349, Residencial San Nicolas, M-7, Serraria, Maceió, AL, Brasil. CEP: 57046-388.

E-mail: glaubermanso@outlook.com

Recebido em 11/08/20; Aceito em 19/09/20. 


\section{INTRODUÇÃO}

Ao final do ano de 2019, em Wuhan, na China, foi relatado o primeiro caso de infecção da síndrome respiratória aguda grave do coronavírus 2 (severe acute respiratory syndrome coronavirus 2 - Sars-CoV-2), causadora da coronavirus disease 2019 (Covid-19)'. Conforme sua característica de alta transmissibilidade, o vírus começou a ser disseminado e alastrou-se pelos cinco continentes, conferindo, em março de 2020, a realidade de pandemia. A política de distanciamento social, proposta pela Organização Mundial da Saúde para tentar conter a disseminação do vírus, desencadeou um aumento na busca por tecnologias que facilitam a comunicação, como uma forma de manter o ensino acadêmico.

No que tange aos cursos de Medicina, a adoção das Diretrizes Curriculares Nacionais dos Cursos de Graduação Medicina (DCN) viabilizou o processo de autonomia do estudante, tornando-o um agente responsável também pelo próprio aprendizado, além de abrir espaço para a introdução das tecnologias digitais de informação e comunicação (TDIC). Nesse ínterim, a utilização de plataformas on-line para o ensino remoto é uma alternativa viável para amenizar os efeitos causados na educação, tendo em vista a paralisação das atividades presenciais. Apesar de não serem inteiramente suficientes para solucionar os problemas, as TDIC são uma ferramenta-chave no desenvolvimento de modelos educativos integradores ${ }^{2}$. Essas tecnologias conferem aos professores, aos alunos e às instituições de ensino a capacidade de adequação aos meios disponíveis para minimizar prejuízos. Para tal feito, é imprescindível que a educação realizada por vias digitais seja, de fato, de qualidade, sendo necessária a busca por modelos de ensino-aprendizagem que instiguem um ambiente colaborativo em todos os envolvidos ${ }^{3}$. Isso reflete, portanto, a necessidade de modificação de comportamento por parte das instituições de ensino, docentes e discentes ${ }^{4}$.

Com a finalidade de tentar minimizar os prejuízos decorrentes da suspensão das atividades presenciais, a Universidade Federal de Alagoas (UFAL) elaborou a proposta de monitoria on-line, na qual ex-monitores, de períodos anteriores, poderiam ministrar cursos remotos utilizando as tecnologias possíveis e sob orientação de docentes responsáveis. No que tange à escolha da temática, considera-se que a anamnese possui potencialidade para o reconhecimento do outro, das necessidades e dos desejos implícitos, dos medos e das ansiedades dele. O seu reconhecimento é relevante na formação, já que o estudante terá, nessa ferramenta, a base para o exercício profissional5. Por ser o assunto-base do primeiro período do curso de Medicina da UFAL, Campus Arapiraca, a anamnese foi o tema escolhido pelos monitores para a execução da proposta. Assim, a compreensão dos conceitos teóricos e práticos da anamnese e sua relevância para a prática médica foram os produtos esperados ao final do curso ministrado.

\section{RELATO DE EXPERIÊNCIA}

A construção da monitoria on-line ocorreu de forma remota por meio de plataformas digitais voltadas para a comunicação, como o Google Meets ${ }^{\circledR}$, WhatsApp ${ }^{\circledR}$ e portal do serviço de conferência web da Rede Nacional de Ensino e Pesquisa (RNP). Foram necessárias duas semanas para a elaboração do calendário de atividades, além da produção e edição dos podcasts. A elaboração do conteúdo ocorreu de forma conjunta entre os monitores e sob supervisão dos docentes.

O curso contou com 54 inscrições de alunos de Medicina. Com o intuito de acompanhar o grau de envolvimento dos alunos no curso, foi proposta uma participação mínima de 70\%, o que correspondia a responder no mínimo cinco das sete atividades propostas durante o desenvolvimento das aulas, além de acompanhar os podcasts e as webconferências. Ao final do curso, 38 alunos cumpriram os requisitos mínimos para certificação. Assim, 70,3\% ( $n=38)$ finalizaram o curso on-line.

Fez-se necessária a construção de um ambiente virtual, em que houvesse fácil acesso aos conteúdos, organização e interação dos alunos com os monitores e docentes. Essa possibilidade foi idealizada no Padlet ${ }^{\circledR}$, uma vez que, por ser um "mural virtual" interativo e dinâmico, tornou-se uma grande ferramenta educacional que aprimorou a construção do curso on-line (Figura 1). A plataforma permite anexar os conteúdos teóricos, as dúvidas e as atividades extras, além dos podcasts e das webconferências. Além disso, o Padlet ${ }^{\circledR}$ permitiu acesso irrestrito aos alunos, admitindo a autonomia do estudante ante os estudos.

Para manter a proposta de autonomia do aluno e de acesso ilimitado ao conteúdo, produziram-se 22 podcasts com duração média de quatro minutos. Esse material foi elaborado na plataforma Anchor ${ }^{\circledR}$ e hospedado nesse aplicativo e no Spotify ${ }^{\circledR}$. No que tange às reproduções, alcançaram-se 984 durante as oito semanas de curso, e o podcast intitulado "Semiotécnica da anamnese" obteve 83 acessos (Figura 2). Para agregar fundamentos teóricos ao estudo, havia a possibilidade de associá-lo às referências sugeridas, as mesmas utilizadas para elaboração dos podcasts e webconferências. Vale destacar que o material ficou disponível também ao público geral após o final do curso.

Visando ao aperfeiçoamento do ensino, os cursistas tinham acesso aos formulários feitos no Google ${ }^{\circledR}$, os quais continham questões, em forma de casos clínicos, acerca do conteúdo abordado nos podcasts da semana. Assim, para proporcionar maior absorção do conteúdo teórico, foram 
Figura 1. Layout do "mural virtual” do Padlet ${ }^{\circledR}$ utilizado durante o curso

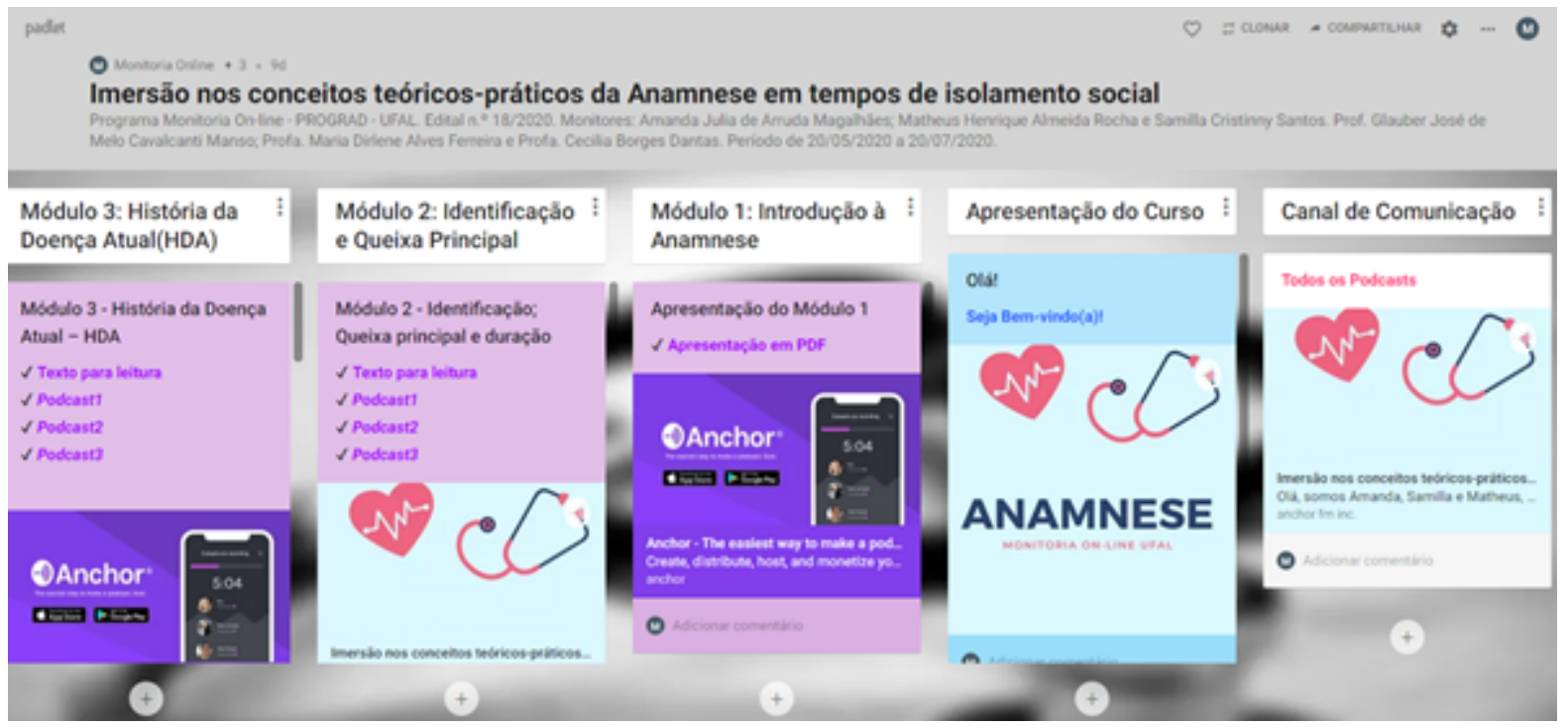

Fonte: Site da plataforma Padlet ${ }^{\circledR}$.

Figura 2. Performance do número de reproduções dos podcasts ao longo dos meses do curso

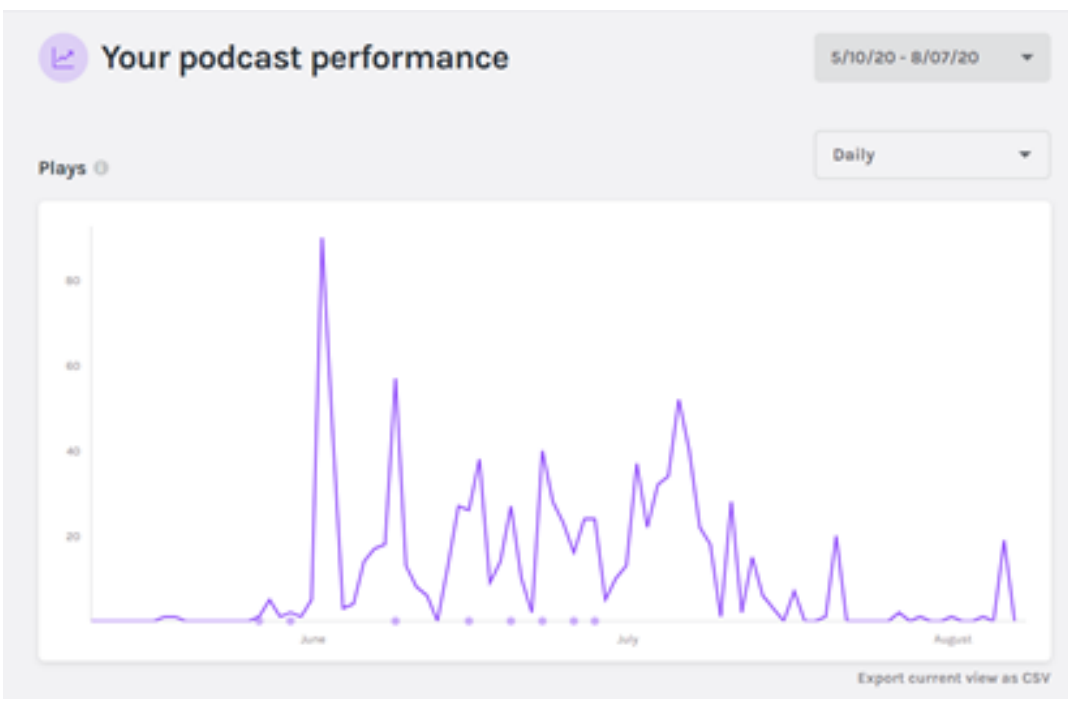

Fonte: Site da plataforma Anchor ${ }^{\circledR}$.

disponibilizadas 20 questões durante o curso, divididas em seis formulários que continham, cada um, uma média de 44 respostas. Dessa forma, foi possível realizar a complementação do estudo com as referências propostas. Além disso, cada formulário continha um espaço destinado para as dúvidas referentes aos assuntos discutidos, os comentários sobre os módulos e as sugestões para a melhoria do curso. Os questionários também foram disponibilizados com uma semana antes da webconferência, a fim de que os alunos tivessem tempo suficiente para realizar a busca ativa do conteúdo teórico e, em seguida, pudessem esclarecer as possíveis dúvidas das atividades propostas durante o encontro virtual.

Para a mediação dos encontros on-line, utilizaram-se as plataformas digitais Google Meets ${ }^{\circledR}$ e portal do serviço de conferência web da RNP, que permitiam a interação dos estudantes inscritos do curso com os monitores e os docentes supervisores da monitoria on-line. As reuniões ocorriam às terças-feiras, no período da tarde, durante o período de desenvolvimento do curso, com duração média de uma hora e voltavam-se para a dúvidas pertinentes dos alunos sobre os assuntos da semana anterior. Por ser uma ferramenta digital, os alunos poderiam acessá-la por seus celulares ou computadores/ notebooks, o que foi um elemento facilitador para a interação. Além disso, no decorrer da webconferência, outras possíveis dúvidas surgiam e muitas eram explicadas de forma síncrona pelos monitores e docentes durante a apresentação.

Como forma de proporcionar um estudo mais ativo e dinâmico, em consonância ao uso das metodologias 
ativas, utilizou-se o aplicativo móvel Kahoot ${ }^{\circledR}$ para mediar essa interação. Por meio desse aplicativo, os estudantes participavam de jogos de perguntas com limite de tempo estipulado que envolviam o conteúdo abordado nas aulas, além de saberem a posição no ranking ao final do jogo, em comparativo ao restante dos alunos. Essas atividades eram disponibilizadas meia hora antes do início da webconferência. Além disso, as perguntas do jogo eram baseadas em dúvidas apresentadas pelos próprios alunos no Padlet ${ }^{\circledR}$ durante a semana, o que conferiu a todos os estudantes a possibilidade de responderem aos questionamentos dos colegas.

A atividade final foi pensada para consolidar o aprendizado do conteúdo teórico e consistia na elaboração de uma anamnese pelos cursistas e sua posterior correção por pares de forma anônima. A preparação dessa atividade se deu a partir da demonstração, pelos monitores, de um modelo de anamnese em uma das webconferências, na qual os alunos puderam sanar as suas principais dúvidas sobre a escrita da anamnese. Em seguida, os alunos realizaram a construção da anamnese com auxílio de um membro de sua família de forma presencial ou remota. Após isso, os monitores receberam as anamneses e fizeram a randomização, de forma manual, delas para correção de forma anônima por outros três alunos. Eles receberam orientações e um checklist com os critérios avaliativos necessários. As categorias foram as seguintes: identificação; queixa principal e duração; história da doença atual; interrogatório sintomatológico; antecedentes pessoais; antecedentes familiares; hábitos e estilo de vida; e condições socioeconômicas e culturais (Figura 3). A partir disso,

Figura 3. Resultado da correção feita pelos alunos na atividade final

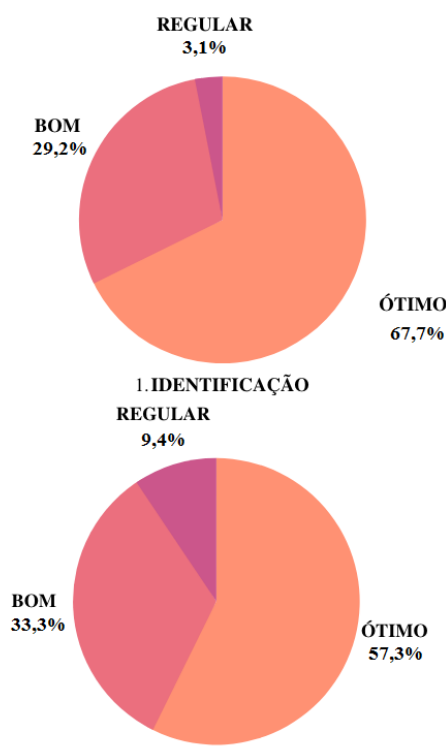

3. HISTÓRIA DA DOENÇA ATUAL
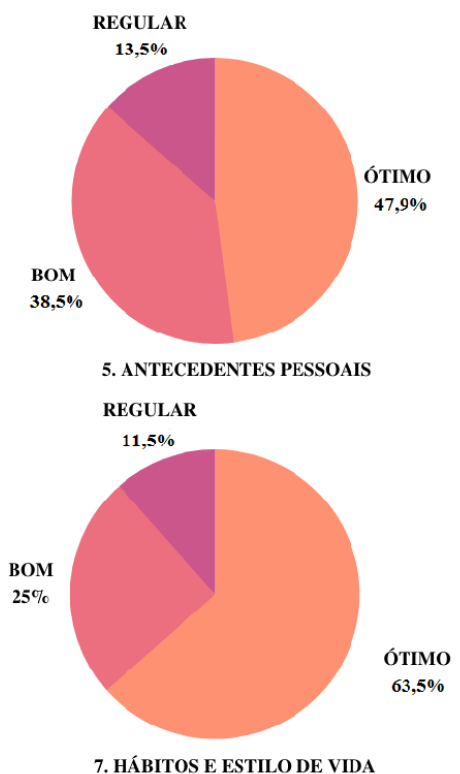

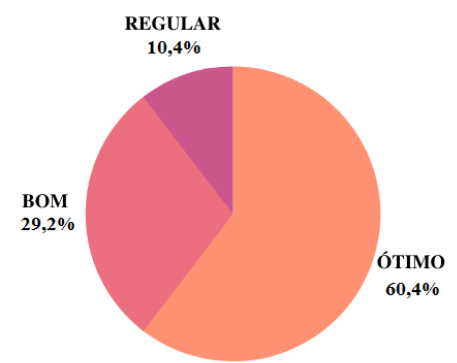

2. QUEIXA PRINCIPAL E DURAÇÃO REGULAR

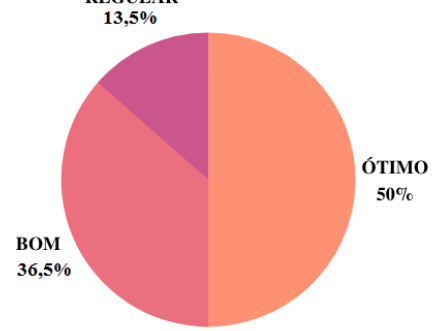

4. INTERROGATÓRIO SINTOMATOLÓGICO

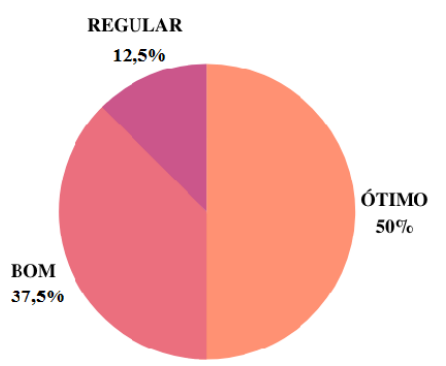

6. ANTECEDENTES FAMILIARES

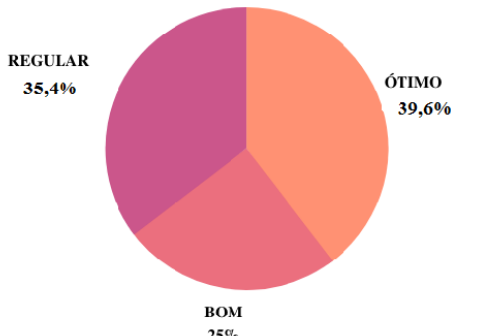

8. CONDIÇÕES SOCIOECONÔMICAS E CULTURAIS

Fonte: Formulários Google ${ }^{\circledR}$. 
selecionaram-se os principais pontos positivos e negativos para construção do último encontro, no qual se esclareceram as últimas dúvidas, destacou-se a importância da anamnese e realizou-se o feedback final.

\section{DISCUSSÃO}

A construção da sociedade do século XXI é pautada na organização e no funcionamento por meio das tecnologias digitais, sendo a educação um campo que também recebe interferência constante desses meios. Logo, há inerentes mudanças que interessam aos estudos e os impactam de forma positiva, possibilitando aumento da produtividade, autonomia e facilitação na construção da aprendizagem, em virtude do acesso às informações por meio de plataformas digitais que permitem novos tipos de interação e comunicação graças às atuais tecnologias disponíveis ${ }^{6}$.

Concomitantemente, as TDIC impulsionaram o processo de autonomia do estudante no seu aprendizado, após a reforma dos cursos de graduação em Medicina com a implantação das novas DCN, as quais atuam como forma de alicerçar o ensino e a aprendizagem na medicina?. Assim, diante da atual pandemia causada pela Sars-CoV-2, em que o ensino presencial foi totalmente restringido, a fim de evitar aglomerações, viu-se uma grande oportunidade com o uso das TDIC para a manutenção do conhecimento por meio do ensino remoto nos cursos médicos.

O ensino híbrido, uma realidade já existente nos cursos a distância, é uma alternativa à paralisação das atividades educacionais, haja vista o fato de possibilitar a aprendizagem em tempos e locais diferentes. No entanto, essa abordagem tem sido alvo de constantes discussões que colocam em pauta as barreiras geradas pela introdução de alternativas remotas em um ensino anteriormente presencial. Esses obstáculos referem-se a fatores como problemas relacionados ao acesso à internet e a dispositivos eletrônicos, como smartphones e computadores, a dificuldade em manter a concentração nas atividades, além da ausência de capacitação necessária aos docentes na utilização de tecnologias ${ }^{8}$.

Anteriormente a esse cenário, o uso das tecnologias no ambiente educacional já se encontrava em plena ascensão em países desenvolvidos, como a Coreia do Sul. Um estudo de Kyong-Jee Kim e Giwoon Kim realizou uma abordagem sobre o desenvolvimento do e-learning, que trata da aprendizagem apoiada ou mediada por tecnologias nas escolas médicas durante um período de dez anos. Foram utilizados diferentes recursos para promover o aprendizado, como vídeos, imagens clínicas, áudios, formulários, casos clínicos e animações online. Esses recursos permitiram uma maior efetividade na consolidação do conteúdo, já que ocorreu uma adequação da aprendizagem aos diferentes perfis de alunos. Assim, essas ferramentas complementam o conhecimento recebido e proporcionam um estudo em que o aluno participa ativamente no processo de ensino-aprendizagem, tanto nos momentos de ensino síncronos quanto nos assíncronos. Percebe-se que há uma tendência de que ocorra uma maior inserção dessas tecnologias no desenvolvimento de um novo modelo educacional, principalmente no momento pós-pandemia.

Para tal feito, a utilização de plataformas que viabilizem a interação do aluno com o conteúdo é necessária, de forma a não adquirir o caráter totalmente expositivo nas aulas. Sem a interação entre os membros envolvidos, o aluno torna-se um receptor meramente passivo das informações, o que atrapalha na formação do pensamento crítico ${ }^{10}$. Essa característica, bastante tradicional ainda no ensino médico, continua, na maioria dos casos, pautada na transmissão oral e presencial do conhecimento, em que o ensino é centralizado no docente, tornando o discente apenas receptor e reprodutor dos conteúdos em sala. Com a manutenção desses métodos pedagógicos, conforme essa conduta de aprendizagem tradicional, há uma maior relutância na adoção das novas tecnologias voltadas para o ensino ${ }^{11}$. Assim sendo, essa cultura de ensino nas universidades perpetuase e se restringe apenas a informar o aluno e não o instiga, limitando a autonomia do aprendizado ${ }^{12}$. Isso corrobora, consequentemente, o abandono das atividades por parte dos estudantes. Portanto, o uso de material audiovisual, jogos, videoconferências, questionários e ambientes para dúvidas é importante para conferir à aprendizagem on-line o caráter dinâmico e interativo. Além disso, permite a facilidade no acesso a uma ampla variedade de informações, conferindo um modelo de aprendizagem personalizada para a realidade do aluno e, assim, torna-se o cerne do conhecimento, alcançando esse espaço sob as orientações e o apoio do corpo docente para a utilização eficaz das tecnologias ${ }^{11}$.

No que tange à utilização das TDIC, elas fornecem subsídios para formação e atualização do ensino médico por meio dos aparatos tecnológicos, visto que promovem maior inserção das atividades de caráter prático com os assuntos teóricos em sala de aula, auxiliadas por esses espaços virtuais de aprendizagem ${ }^{12}$. Além disso, conforme mostra um estudo de revisão bibliográfica sobre o uso das tecnologias nos cursos de graduação em Odontologia, a utilização da tecnologia para o ensino remoto corrobora a reconfiguração da aprendizagem ${ }^{13}$. A aplicação da internet e das mídias digitais na educação pode tornar o ensino mais atrativo e interativo ao aluno, o que resulta em atividades educacionais mais prazerosas.

Nesse contexto, está inserida a gamificação na educação do ensino superior que, a partir da utilização de jogos, em que 
os alunos, com o seu conhecimento prévio, interagem com dinamicidade e engajamento, como é o caso da plataforma Kahoot ${ }^{\circledR}$, possibilita o aprimoramento na consolidação do conteúdo e no exercício da agilidade e estratégia do pensamento crítico, imprescindível à prática médica ${ }^{14}$. Nesse sentido, a gamificação possui a capacidade de combater o desinteresse existente entre os alunos pelas formas tradicionais de ensino que ainda não levam em conta a realidade em que eles estão inseridos ${ }^{15}$. Uma pesquisa realizada pelo portal Learning \& Peformance Brasil questionou os profissionais quanto ao uso de games aplicados ao e-learning. Eis alguns dos resultados dessa pesquisa: $78 \%$ dos profissionais consideraram que, ao utilizarem essas estratégias, tiveram boa retenção, enquanto $22 \%$ responderam que obtiveram média retenção; 94\% afirmaram que a gamificação possuía desempenho e a capacidade de avaliação; e $96 \%$ concordaram que os jogos educativos estavam mais adaptados ao mundo atual do que o modo tradicional de ensino ${ }^{16}$. Além disso, usar os formulários on-line permitiu, além da resolução das questões, a sugestão de melhorias para o curso, comentários e espaço para dúvidas. Esse espaço possibilitou a interação com o aluno ao longo da construção do curso. Logo, em uma sociedade imersa em tecnologia, não se pode ignorar o potencial dos meios digitais quando incorporados ao ensino-aprendizagem ${ }^{17}$.

O uso dos podcasts mostrou-se uma ferramenta importante no processo de ensino-aprendizagem do conteúdo da anamnese para os cursistas. À medida que oferece os materiais didáticos na forma de áudio, com acesso ilimitado e o conteúdo apresentado de forma flexível em poucos minutos, facilita o aprendizado para aqueles que têm pouco tempo disponível, mas se interessam em aprender ${ }^{18}$. Um estudo qualitativo avaliou a capacidade de os podcasts médicos produzirem impacto no processo educacional dos seus ouvintes. Com base na percepção destes, observou-se que o podcast foi utilizado enquanto os ouvintes realizavam outras tarefas, como dirigir até o local de trabalho. Também foi utilizado para promover atualização a partir da discussão de artigos relevantes da literatura médica, e, assim, houve a construção do conhecimento de uma forma mais interativa. Os ouvintes entrevistados consideraram que os podcasts, indiretamente ou ao longo do tempo, impactaram a prática médica ao permitirem acesso ao conhecimento científico ${ }^{19}$. Dessa forma, é notório que o podcast é uma alternativa de grande potencial ao material disponível em forma de textos e, consequentemente, confere ao conteúdo maior acessibilidade, possibilitando que, mesmo com algumas limitações, várias pessoas tenham oportunidade de aprender.

Uma das grandes contribuições da monitoria, no formato tradicional e presencial, no ensino acadêmico médico é proporcionar ampliação e protagonismo no ensinoaprendizagem, uma vez que a interação entre monitores e alunos necessita de uma abordagem que se adapte às diversidades da turma e requer estratégias para superar as dificuldades no aprendizado. Todavia, uma das grandes dificuldades para maior participação nesse estilo de monitoria é a falta de tempo na grade curricular dos monitores, o que diminui o interesse dos discentes por esse tipo de atividade durante a graduação e, consequentemente, a participação deles nas atividades. Outro fator é a dificuldade em encontrar horários comuns a monitores e discentes, o que leva os estudantes a buscar as monitorias apenas em datas antecedentes às provas. Assim, a extensa carga horária acadêmica não permite uma participação mais assídua dos discentes e reflete também na escassez de diversidade no ensino que poderia ser aproveitado nesses momentos ${ }^{20}$. Como forma de superar tal barreira, uma dessas possibilidades seria a monitoria on-line pelo fato de tornar-se um canal de educação contínuo, em razão de seu caráter virtual em que os materiais de estudos previamente disponibilizados pelos monitores podem ser hospedados, da independência do ato presencial e do amplo repertório de ferramentas tecnológicas que podem ser usadas. Essa experiência foi registrada na literatura em 2003 , na qual se relatou o uso da monitoria on-line para o ensino da epidemiologia no curso de Medicina na Universidade Federal do Rio de Janeiro (UFRJ) ${ }^{21}$. Outra experiência similar foi realizada no curso de Enfermagem, como forma de monitoria on-line, a partir de $2008^{22}$, ratificando a necessidade de atualização intensiva no ensino mediado por tecnologias, visto que os estudos com essas propostas são escassos e antigos na literatura e possuem potencial de promover grandes impactos no sistema educacional médico, principalmente no atual panorama da pandemia da Covid-19. O presente relato da monitoria on-line sobre a anamnese promovida pela UFAL mostra o caráter inovador e pioneiro com uso de diversas ferramentas digitais voltadas para o conhecimento da medicina.

Logo, o conceito da educomunicação, ações com o objetivo de produzir espaços educativos virtuais ou presenciais que ampliam o processo de aprendizagem, é ratificado com a utilização dessas plataformas tecnológicas ${ }^{18}$. Dessa maneira, no contexto de pandemia, é perceptível que o ensino remoto, quando bem explorado, estimula o aluno a buscar meios de adquirir conhecimento mesmo quando as aulas presenciais são interrompidas.

\section{CONCLUSÃO}

A monitoria on-line permitiu a consolidação das bases teóricas necessárias para a construção da anamnese, conteúdo predominantemente prático na modalidade presencial de ensino, associada à realização da anamnese na íntegra 
como produto final esperado do curso. Mesmo sendo uma atividade extracurricular, de caráter não obrigatório, obtevese considerável número de inscritos que concluíram o curso, e, assim, considera-se o êxito na execução do projeto. Assim, graças ao suporte tecnológico, conteúdos de caráter prático podem ser discutidos e explicados.

Para tal feito, foram imprescindíveis métodos colaborativos de construção do saber que permitissem ao cursista a interação com o conteúdo de maneira ativa. Assim, o curso não adquiriu caráter meramente expositivo, o que aumentaria, consequentemente, o índice de abandono das atividades. Dessa forma, o aluno era também responsável pela própria aprendizagem. Percebe-se, portanto, a efetividade na utilização de tecnologias no processo de ensino-aprendizagem sobretudo quando se empregam plataformas de qualidade e há adesão dos membros envolvidos.

\section{CONTRIBUIÇÃO DOS AUTORES}

Amanda Júlia de Arruda Magalhães, Matheus Henrique Almeida Rocha e Samilla Cristinny Santos contribuíram substancialmente em todas as etapas de execução e planejamento do trabalho. Cecília Borges Dantas, Glauber José de Melo Cavalcanti Manso e Maria Dirlene Alves Ferreira contribuíram com reflexões gerais em todo o trabalho, além de fornecerem suporte na construção do texto.

\section{CONFLITO DE INTERESSES}

Os autores declaram não haver conflito de interesses neste relato.

\section{REFERÊNCIAS}

1. Barreto ML, de Barros AJD, Carvalho MS, Codeço CT, Hallal PRC, Medronho RA, et al. O que é urgente e necessário para subsidiar as políticas de enfrentamento da pandemia de COVID-19 no Brasil? Rev Bras Epidemiol 2020;23:01-04. doi: 10.1590/1980-549720200032.

2. Goudouris ES, Giannella TR, Struchiner M. Tecnologias de informação e comunicação e ensino semipresencial na educação médica. Rev Bras Educ Med. 2013;37(3):396-407.

3. Moreira JAM, Henriques S, Barros D. Transitando de um ensino remoto emergencial para uma educação digital em rede, em tempos de pandemia. Dialogia. 2020;(34):351-64.

4. Carneiro LA, Rodrigues W, França G, Prata DN. Uso de tecnologias no ensino superior público brasileiro em tempos de pandemia COVID-19. Research, Society and Development. 2020;9:01-18. doi: 10.33448/rsdvgi8.5485.

5. Soares MOM, Higa EFR, Passos AHR, Ikuno MRM, Bonifácio LA, Mestieri $\mathrm{CP}$, et al. Reflexões contemporâneas sobre anamnese na visão do estudante de medicina. Rev Bras Educ Med. 2014;38:314-22. doi: 10.1590/ S0100-55022014000300005

6. Costa SRS, Duqueviz BC, Pedroza RLS. Tecnologias digitais como instrumentos mediadores da aprendizagem dos nativos digitais. Psicol Esc Educ. 2015;19:603-10. doi: 10.1590/2175-3539/2015/0193912.
7. Gorgens PRC, Andrade PCR. Estratégias para uso de tecnologias digitais de informação e comunicação no ensino médico construtivista. Anais do Congresso Internacional de Educação e Tecnologias, Encontro de Pesquisadores em Educação a Distância Materiais; 2018; São Carlos; 2018 [acesso em 11 ago 2020]. Disponível em: https://cietenped.ufscar.br/ submissao/index.php/2018/article/view/591.

8. da Silva EHB, da Silva Neto JG, dos Santos MC. Pedagogia da pandemia: reflexões sobre a educação em tempos de isolamento social. Revista Latino-Americana de Estudos Científicos. 2020;1(4):29-44. doi: 10.46375/ relaec.31695.

9. Kim K-J, Kim G. Development of e-learning in medical education: 10 years' experience of Korean medical schools. Korean J Med Educ. 2019;31(3):205-14. doi:10.3946/kjme.2019.131.

10. Pereira TA, Areco KCN, Tarcia RML, Sigulem D. Uso das tecnologias de informação e comunicação por professores da área da saúde da Universidade Federal de São Paulo. Rev Bras Educ Med. 2016;40(1):59-66.

11. O'Doherty D, Dromey M, Lougheed J, Hannigan A, Last J, McGrath D. Barriers and solutions to online learning in medical education - an integrative review. BMC Med Educ. 2018;18(1):130:01-11. doi: 10.1186/ S12909-018-1240-0.

12. Gorgens PRC, Andrade PCR. Educação médica e tecnologias digitais de informação e comunicação: possibilidades e dilemas. Rev Méd Minas Gerais. 2018;28(e-2004):01-10. doi: 10.5935/2238-3182.20180154.

13. Xavier TB, Barbosa GM, Meira CL, Conte Neto N, Pontes HA. Utilização de recursos web na educação em odontologia durante pandemia COVID-19. Brazilian Journal of Health Review.2020;3(3):4989-5000. doi: 10.34119/ bjhrv3n3-081.

14. Martins C, Giraffa LMM, Lima VMR. Gamificação e seus potenciais como estratégia pedagógica no ensino superior. Revista Novas Tecnologias na Educação. 2018;16(1):1-10.

15. Tolomei BV. A gamificação como estratégia de engajamento e motivação na educação. EaD em Foco. 2017;7(2):145-156. [acesso em 29 ago 2020] Disponível em: https://eademfoco.cecierj.edu.br/index.php/Revista/ article/view/440.

16. Fernandes CWR, Ribeiro ELP. Educação e tecnologias: aprendizagem e construção do conhecimento. Anais do Congresso Internacional de Educação e Tecnologias, Encontro de Pesquisadores em Educação a Distância Materiais; 2018; São Carlos; 2018 [acesso em 29 ago 2020]. Disponível em: https://cietenped.ufscar.br/submissao/index.php/2018/ article/view/344.

17. Silva JMA, Canedo RV, Abrantes TAS, Santos RT, Souza RA, Utagawa CY. Quiz: um questionário eletrônico para autoavaliação e aprendizagem em genética e biologia molecular. Rev Bras Med. 2010;34(4):607-14.

18. Gomes RMCM, Alencar MP, Santos MJMN, Silva RS, Messias JB, Florêncio MS. Redes de colaboração. Anais do IV Congresso sobre Tecnologias na Educação (Ctrl+e); 28-30 ago 2019. Porto Alegre: Sociedade Brasileira de Computação; 2019 [acesso em 11 ago 2020]. Disponível em: https://sol. sbc.org.br/index.php/ctrle/article/view/8886.

19. Malecki SL, Quinn KL, Zilbert N, Razak F, Ginsburg S, Verma AA, et al Understanding the use and perceived impact of a medical podcast: qualitative study. JMIR Med Educ. 2019;5(2):e12901. doi: 10.2196/12901.

20. Botelho LV, Lourenço AEP, de Lacerda MG, Wollz LEB. Academic monitorship and professional training in health: an integrative review. ABCS Health Sci. 2019;44(1):67-74. [acesso em 10 set 2020]. Disponível em: https://www.portalnepas.org.br/abcshs/article/view/1140.

21. Soares ALAG, Dias CP, Vidal EIO, Coeli CM, de Almeida LM, de Camargo Júnior KR. Utilização de um serviço de monitoria virtual voltado para o ensino de epidemiologia na graduação médica. Physis. 2003;13(1):39-58. doi: 10.1590/S0103-73312003000100003.

22. Gogo ALP, Rozeno R, Bonmann DMS, Azambuja MI. Monitoria a distância em disciplina do curso de graduação em enfermagem: relato de experiência. Anais do $18^{\circ} \mathrm{CIAED}$ Congresso Internacional ABED de Educação a Distância; 2012; São Luís, MA. Associação Brasileira de Educação a Distância - ABED. 